tant psychiatrist could operate in the following roles:

(i) Leadership: Leadership, whether exclusive or shared, is essential and must be founded on a broad education and an appropriate temperament. It must be earned rather than regarded as God-given. The strictly medical and conventional component of the consultant's skill is, of course, necessary in psychiatry but it is not always sufficient. Some knowledge of psychology, sociology, management, the processes of education, and even the arts is also desirable if the clinical orchestra is to be wisely conducted.

(ii) Special skills: Within the complexity of modern psychiatry special skills will be needed and interest and practice in these fields will promote job satisfaction. The skills may be derived from strictly medical/biological models, from more psychologically-orientated disciplines, or from special client groups such as forensic and psychogeriatric.

(iii) The general psychiatric role (community psychiatry?): With the development of care beyond hospitals, particularly if this care is to be truly primary, it will be necessary for a consultant, even though he is highly skilled within some area of psychiatry, to practise also in a more general role. When bearing their own psychiatric case load GPs will require ready specialist support. Each locality will need at least one consultant who is known, who is readily available and to whom the GP can turn for advice. Between them they can work out their styles of interaction, including decisions about constraints, limits and priorities. In this respect the consultant acting is different from either of the roles previously described. He is the facilitator who knows the community and is known to it. He will also need an allocation of time in addition to that devoted to special skills and leadership.

(iv) Miscellaneous roles: Teaching, management, research and public relations are all roles that should be embraced by consultants, providing again that the true cost in time and finance is accounted for. They could perhaps be regarded as special skills within category (ii), but the essence of the present hypothesis is that there is a difference between the approach dependent on special skills and the approach dependent on getting to know a locality and its problems.

A model such as the above, through its specialist roles, would allow the consultant to express his individual interests, skills and styles with a consequent increase in job satisfaction. It would also value and set in perspective service to a community as complementary to special skills and go some way to avoiding prejudicial distinctions between hospital and community practice.

Within a District it would be the responsibility of management to see that a range of consultant skills, appropriate to the needs of the whole community, is provided. Individual clinicians would cross refer when their own special skills were insufficient to meet the needs of a patient from their own local community.

REFERENCE

JoNEs, K. (1982) Scull's Dilemma. British Journal of Psychtatry, $141,221-6$.

\title{
Zimbabwe's New Diploma in Psychiatric Health
}

\author{
W. MURDoch, Consultant Psychiatrist, Harare, Zimbabwe
}

Psychiatry in a land of $7 \frac{1}{2}$ million (National Census, August 1982) people with relatively advanced general medical services, but only eight psychiatrists, has great problems. The facilities have been described elsewhere (Murdoch, 1982). Historically poorly related to population needs, and with immense difficulties in serving the rural communities that still comprise over half the population (National Census), Zimbabwe has concentrated its post-independence effort on the development of primary health care in village, district and small town. With a medical school expanding (current intake 80 students per annum) and good central facilities for training and specialist care, primary care in public health and general medical services are developing on a sound basis. In psychiatry, a mere 1200 beds for the country (only 141 in the capital, Harare, which, with dormitory towns, has an 'official' population of 1.1 million and serves a further four million in remote rural areas) the training and specialist facilities are sketchy indeed.

The new Government's aim to bring basic health care into the remotest village relies on village health workers (volunteers) and various grades of health inspectors and medical assistant (State Enrolled Nurse) in more central clinics. Through the 55 District Hospitals in the smaller towns and centres, increased training of personnel is intended to diffuse the services of the highly developed general medical centres to the benefit of the whole population, instead of the privileged few in the half dozen major towns.

Psychiatry, too, is being taught to new trainees and at 
refresher courses to health staff throughout the country, and a genuine attempt is being made to treat people as outpatients as near their homes as possible. If day care or admission is required, it is planned to provide this at District General Hospitals, which means building 55 psychiatric units attached to those hospitals, but the care in such wards would be under a General Medical Officer. The four Government and three University Psychiatrists in the country providing a central specialist service (yet to be developed in the capital city) will be hard put to give more than an occasional visit to such centres. It becomes increasingly important that General Medical Officers are encouraged to see the value for this tropical country of a developed expertise in psychiatry. Such a view has not been traditional. Psychiatry, indeed, has been dismissed by many doctors as the province of the traditional healer or spirit medium rather than a part of general medical care and concern. As a consequence, health care workers trained in the districts are unlikely to have gained much confidence, experience or knowledge in the psychiatric field.

Against this background the University has expanded its Medical School Department of Psychiatry in the last ten months from one psychiatric professor on his own to an exciting Department with two senior lecturers in psychiatry, two in Clinical Psychology, an ambitious programme of student teaching (in more or less the British mould, but increasingly Zimbabwean in Application), as well as research and training in clinical psychology (in which there are four probationers).

In this setting there is a shortage of trained care for the 1600 admissions and numerous out-patients seen in the capital's catchment area. From my own personal experience as a District Medical Officer in three African countries, I know that doctors in developing countries are often unaware of their ability to assist with psychiatric problems. 'Psychiatric problems' too often include altered states of consciousness, especially those stemming from the epilepsies and the results of alcohol and marijuana abuse. The few trained RMNs are out-numbered by SRN nurses, who similarly have not been exposed in training or experience to modern methods of mental health care.

The health assistants and other graded staff in rural areas who link clinics with homes in places a hundred miles from a hospital, have only recently benefited from an occasional visit made by a psychiatric nurse to develop their skills in psychiatric management.

A Diploma Course has now been prepared. It is designed to show the way in which psychiatry is a basic and integral part of community health care in the remotest village, and that health workers have a part to play. The idea is to train selected General Medical Officers to be particularly competent with psychiatric problems as they are met in Zimbabwe, and to be able to teach and pass on their skills to nurses and other grades of health staff. In 'more developed' countries, psychiatry is the only important every-day branch of medicine in which a period of experience and simple study cannot be recognized with a diploma for a future general practitioner. Whilst moves to correct this are now under way in the United Kingdom, Zimbabwe, perhaps with the advantage of a fresh start in a neglected area, has been able to present this stimulus to doctors to take a new look at and interest in this basic area of medicine. Further, the training is here in the African setting, and may usefully provide a centre for neighbouring countries too.

Training will emphasize local needs, and is hoped to attract Zimbabwean graduates, who have been sadly lacking from the ranks of psychiatrists in past years. Whilst doubtless the cross-cultural worker has insights the 'local' lacks, he certainly has enormous difficulties in psychiatric practice when his colleagues all share the same handicap of foreign origin, as well as lack of local idiom or language and dialect fluency.

The Diploma will be called D.Psych.H. (Diploma in Psychiatric Health), and will be administered by the Institute of Continuing Health Education through a Board of Studies within the University of Zimbabwe. Candidates holding the M.B., Ch.B. degrees and having completed a one-year internship will be able to enter the course. This is a one-year parttime training course, whilst the candidate is employed in an approved post within the country. At the end there will be examination by written, clinical and oral methods.

The training course commenced in July 1982 in the setting of the almost excessive wealth of clinical material to be found in any department in a developing country. The history of psychiatry, its modes of studying patients and treating them, basic study of psychology, and a review of clinical neurology will be included. Local problems will play a large part in the syllabus, as well as the experience of trainees. Where beds are almost a token provision, the possibilities inherent in treating patients at home, and developing community care services to make this possible, will be much explored and emphasized. Trainees will be instructed in the principles of teaching mental health to health workers of all kinds, including not only nursing staff, but medical assistants, health inspectors, rural health workers and ultimately the village health workers. There will be short attachments to a Neurology Department, and also to a Rural Health Centre.

Social and cultural issues will receive appropriate emphasis, while the full range of psychiatric disorders are seen in this, as in any other country. The presentation is coloured by the social background of the patients, and in the post-independence era, there is a tremendous interest in traditional methods of coping with those who are mentally ill. Psychiatry practised at any level must take into account the influence of treatment by the traditional healer, which often also provides much of the necessary social work and rehabilitation. Probably more significant for the future than this is the tremendous and rapid growth of cities, with the cultural shock of the change from rural to city and industrial life. Indeed, a very high proportion of Zimbabwean 
society live with a home in the city as well as in the country.

In this way it is hoped that D.Psych.H. (University of Zimbabwe) will help to reverse the tendency in developing countries for doctors to lose sight of the immense amount of suffering caused by mental illness and mental retardation, when confronted with problems of developing a general medical service and an effective public health system. It is very much hoped that this one-year course will also serve as an introduction to a full course leading to Specialist Regis tration for those with the aptitude and will to become fulltime psychiatrists. Plans are indeed well-advanced within the University for a higher degree, which could be obtained within the country, without sacrificing trained manpower to spend long periods in Europe or elsewhere.

The pioneer course is for Zimbabweans. But in spite of (or perhaps because of the local cross-cultural emphasis in the training, this postgraduate diploma may later be seen as an attractive qualification for those planning future carcers in general practice in other countries, including Britain.

\section{REFERENCE}

Murdoch, W. (1982) Chapter 3 in Mental Health in Africa (eds. O. A. Erinosho and N. W. Bell). Ibadan University Press.

\section{Reviews}

Elements of a Comprehensive Local Service for People with Mental Handicap. Independent Development Council. 1982. Pp. 40. £1.00.

Better Services for the Mentally Handicapped? Lessons from the Shefiteld Evaluation Studies. King's Fund Project Paper No. 34. 1982. King's Fund Centre. £1.50.

Development Team for the Mentally HandicappedThird Report, 1979-81. DHSS. HMSO. Pp. 50. $£ 2.95$.

A major problem in developing appropriate services for mentally handicapped people is the rapidity with which thinking has changed, and continues to do so. The emerging philosophy and principles of care are thus embodied in a succession of policy statements, and in consequence many do not reach lay and professional planners in a coherent and complete form. The Independent Development Council, a partnership of voluntary organizations, professionals and consumers, established in 1981, seeks to rectify this in its publication, Elements of a Comprehensive Local Service for People with Mental Handicap. Well balanced and easy to read, this amply fulfils its aim to provide an up-to-date and concise guide for lay decision-makers on principles of care and the basic requirements for a good, locally based service. Due emphasis is given to the care of the elderly mentally handicapped, sheltered work for the mildly handicapped and guidelines for maternity units on procedures to be followed in the event of the birth of a handicapped baby-aspects which hitherto have received little attention and the importance of enabling mentally handicapped people to have a say in their own affairs and in the development of services is rightly stressed.
Principles and policies are one thing, putting them into practice is another, and all concerned with the development of services for the mentally handicapped will find much of value and interest in the King's Fund Project Paper No. 34, Lessons from the Sheffield Evaluation Studies. This small booklet, which summarizes 13 detailed and substantial reports, is an admirable and much needed example of how to present the results of research in a helpful and readable form for planners and service providers. Drawing upon the Sheffield experience, the Research Director spells out in a refreshingly frank account, the difficulties encountered in translating ideals into reality and the lessons to be learned. He concludes that the key to successful service development is effective partnership between the families, neighbourhood community and public and voluntary service agencies, an accepted basic philosophy, explicit objectives, a workable delivery structure, adequate resources and, above all, sustained commitment.

But according to the Third Report of the Development Team for the Mentally Handicapped, this combination is all too rarely found. The Report covers the past two years' work, and may fairly be said to reflect the current scene countrywide. Commenting on the disappointingly slow rate of service developments, the report cites lack of effective inter-agency collaboration and proper strategic planning as major factors. It points out that these must be speedily remedied if the new opportunities presented by NHS reorganization and Care in the Community are to be fully exploited and the best use made of scarce resources. The present economic situation is another undoubted factor, its impact highlighted by cutbacks in existing provision in some areas, and in others, completed capital projects (such as new hostels) put into mothballs because of an inability to meet 